\title{
Epidemiology of major congenital heart defects in Sweden, 1981-1986
}

\author{
Pierre Pradat
}

\begin{abstract}
Study objective-The aim was to make an epidemiological study of major congenital heart defects and to make comparisons between groups of heart defects regarding different epidemiological variables.

Design-The cases with congenital heart defects were identified from two Swedish registries: the Registry of Congenital Malformations and the Child Cardiology Registry. A classification with nine groups of heart defects is proposed.

Setting-This was a national survey in Sweden during the period 1981-1986. The total number of cases reported during the six years was 1605 . Cases that presented a patent ductus arteriosus only and a birthweight below $2500 \mathrm{~g}$ were excluded.

Measurements and main results-The prevalence at birth was 2.8 per 1000 . When cases with a chromosomal anomaly were excluded, no maternal age effect was observed except a possible under-risk for women above $\mathbf{4 0}$ years. The risk for a heart defect seems to increase with increasing parity independent of age. A higher risk was also observed among twin infants compared with singletons although no specificity in cardiac malformation type appeared. Sex ratio, the tendency for having an associated extracardiac malformation, and the proportion of isolated $v$ non-isolated cardiac defects differed between the different groups of heart malformations.

Conclusions-The differences observed between groups of defects indicate different aetiologies and show that this classification may be suitable for further analyses of congenital heart defects.
\end{abstract}

Congenital cardiac defects are relatively frequent malformations with a prevalence at birth of nearly one per cent. They represent a very heterogeneous group of malformations from the point of view of both pathogenesis and clinical significance. The rate found in a population will depend on inclusion or exclusion of less serious forms. This will also affect studies on the aetiology of cardiac defects. It is therefore important to subdivide the cardiac defects into meaningful more uniform groups which can be suitable for studies on aetiology, recurrence risks, etc.

In this study, two Swedish registries are used to identify cases of congenital heart disease in the country during the period 1981-1986. A description of the material is given, with a proposed grouping of the defects. A specific stress is laid on various epidemiological characteristics.

\section{Methods}

The data were collected from two Swedish registries. ${ }^{1}$ (1) The Registry of Congenital Malformations was started in $1964^{2}$ and is based on the reporting of Swedish newborns with serious malformations diagnosed during the first week of life. All livebirths and stillbirths after the 28th week of gestation are included. The criterion for registration of a heart defect is that it should, during the first week of life, give cyanosis or cardiac failure, or result in death. Infants are registered only when reported within 6 months after birth. (2) The Child Cardiology Registry, formed in 1980, identifies infants with a cardiac defect diagnosed at one of the four child cardiology centres in Sweden during the first year of life. These four paediatric cardiology units are located in Stockholm, Uppsala, Lund, and Gothenburg. Only infants with a heart defect diagnosed by echocardiography, cardiac catheterisation, at operation, or at necropsy are included. Up to four extracardiac malformations can also be registered. Patent ductus arteriosus in infants younger than three months is not recorded.

The heart defects are reported in plain language and are coded with a slightly modified three digit ISC code. ${ }^{3} \mathrm{Up}$ to eight such codes can be given to each infant. Information may be supplemented or modified up to the age of two years.

\section{GROUPING OF CARDIAC DEFECTS}

A grouping of the cardiac defects was made into nine main groups, four of which were divided into subgroups, and a new two digit code was given to each group as shown in table I which also gives for each code the number of infants with that code and the percentage of all codes.

The first group represents the truncus anomalies (codes 10-15) and includes: common truncus, transposition of the great vessels, double outlet right ventricle, pulmonary valve anomalies (including tetralogy of Fallot), aortic valve anomalies (except hypoplastic left heart syndrome), and other truncus anomalies.

The second group is characterised by septal defects (atrium and/or ventricle; codes 20-23).

The third and fourth groups represent the mitral (code 30) and tricuspid (code 40-41) valve anomalies, respectively. In the former, hypoplastic left heart syndrome is not included.

The fifth group is hypoplastic left heart syndrome (code 50), and the sixth is endocardial cushion defect (code 60).

The seventh group represents artery malformations (codes 70-72) and includes: aortic 
malformations (except coarctation), pulmonary artery malformations, and ductus anomalies.

The eighth group represents coarctation of the aorta (code 80), and the last category includes all other cardiac malformations (code 90).

For the cases with only one reported heart defect, a computer program was used to transform the codes. The diagnoses of infants with several reported heart defects were studied one by one and malformations thought to be secondary to another defect were ignored in the analysis. All cases that presented a patent ductus arteriosus only and a birthweight below $2500 \mathrm{~g}$ have been removed from the material.

Proportions were compared using $\chi^{2}$ tests without Yates' correction.

\section{Results}

During the period 1981-1986, 1605 cases of heart defect were reported in the registries mentioned above, among a total of 573422 births. Originally, 1625 cases were identified but 20 were removed because the diagnosis was not considered as a heart defect. This gives a prevalence at birth of 2.8 per 1000. Table II gives the number of cases, the total number of births, and the prevalence at birth each year. There is no heterogeneity between the years $\left(\chi^{2}=3.15\right.$ at $\left.5 \mathrm{df}, \mathrm{p}>0.05\right)$.

Table I List of the two digit codes used to aggregate the ISC codes. When the first digit of the code is used, nine malformation groups are distinguished. The number of diagnoses is given as isolated (only one cardiac diagnosis) or non-isolated (several cardiac diagnoses). The total number exceeds the total number of infants as a single infant may have several malformations.

\begin{tabular}{|c|c|c|c|c|c|}
\hline Malformation & $\begin{array}{l}\text { Two } \\
\text { digit } \\
\text { code }\end{array}$ & Isolated & $\begin{array}{l}\text { Non- } \\
\text { isolated }\end{array}$ & Total & Percentage \\
\hline $\begin{array}{l}\text { Common truncus } \\
\text { Transposition of great vessels } \\
\text { Double outlet right ventricle } \\
\text { Pulmonary valve anomalies } \\
\text { Aortic valve anomalies } \\
\text { Other truncus anomaly }\end{array}$ & $\begin{array}{l}10 \\
11 \\
12 \\
13 \\
14 \\
15\end{array}$ & $\begin{array}{r}36 \\
174 \\
24 \\
202 \\
33 \\
1\end{array}$ & $\begin{array}{r}15 \\
31 \\
20 \\
72 \\
45 \\
2\end{array}$ & $\begin{array}{r}51 \\
205 \\
44 \\
274 \\
78 \\
3\end{array}$ & $\begin{array}{r}2.4 \\
9.9 \\
2.1 \\
13.3 \\
3.8 \\
0.1\end{array}$ \\
\hline Total & & 470 & 185 & 655 & 31.7 \\
\hline $\begin{array}{l}\text { Atrial septal defect (ASD) } \\
\text { Ventricular septal defect (VSD) } \\
\text { ASD + VSD } \\
\text { Cor bi/triloculare }\end{array}$ & $\begin{array}{l}20 \\
21 \\
22 \\
23\end{array}$ & $\begin{array}{r}41 \\
192 \\
46 \\
31\end{array}$ & $\begin{array}{l}24 \\
84 \\
27 \\
32\end{array}$ & $\begin{array}{r}65 \\
276 \\
73 \\
63\end{array}$ & $\begin{array}{r}3.2 \\
13.3 \\
3.5 \\
3.1\end{array}$ \\
\hline Total & & 310 & 167 & 477 & 23.1 \\
\hline Mitral valve anomalies & 30 & 5 & 28 & 33 & 1.6 \\
\hline $\begin{array}{l}\text { Tricuspidal valve anomalies } \\
\text { Ebstein anomaly }\end{array}$ & $\begin{array}{l}40 \\
41\end{array}$ & $\begin{array}{l}26 \\
12\end{array}$ & $\begin{array}{r}17 \\
6\end{array}$ & $\begin{array}{l}43 \\
18\end{array}$ & $\begin{array}{l}2.1 \\
0.9\end{array}$ \\
\hline Total & & 38 & 23 & 61 & 3.0 \\
\hline Hypoplastic left heart syndrome & 50 & 108 & 22 & 130 & 6.3 \\
\hline Endocardial cushion defect & 60 & 128 & 50 & 178 & 8.6 \\
\hline $\begin{array}{l}\text { Aortic malformations (except coarctation) } \\
\text { Pulmonary artery malformations } \\
\text { Ductus anomalies }\end{array}$ & $\begin{array}{l}70 \\
71 \\
72\end{array}$ & $\begin{array}{r}11 \\
7 \\
39\end{array}$ & $\begin{array}{r}52 \\
29 \\
0\end{array}$ & $\begin{array}{l}63 \\
36 \\
39\end{array}$ & $\begin{array}{l}3.1 \\
1.7 \\
1.9\end{array}$ \\
\hline Total & & 57 & 81 & 138 & 6.7 \\
\hline Coarctation of the aorta & 80 & 66 & 146 & 212 & 10.3 \\
\hline Other malformations & 90 & 43 & 136 & 179 & 8.7 \\
\hline Total & & 1225 & 838 & 2063 & 100 \\
\hline
\end{tabular}

Table II Number of infants with congenital heart defects, total number of births, and prevalence at birth each year.

\begin{tabular}{llllllll}
\hline & 1981 & 1982 & 1983 & 1984 & 1985 & 1986 & Total \\
\hline Number of cases & 258 & 271 & 252 & 281 & 275 & 268 & 1605 \\
Number of births & 94064 & 92748 & 91780 & 93879 & 98461 & 102490 & 573422 \\
Prevalence at birth (per 1000) & 2.74 & 2.92 & 2.75 & 2.99 & 2.79 & 2.61 & 2.80 \\
\hline
\end{tabular}

The 1605 infants had a total of 2849 ISC codes. In $871(54 \%)$ only one code was given, in 430 $(27 \%)$ two codes, in $184(11 \%)$ three codes, in 62 $(4 \%)$ four codes, in $39(2 \%)$ five codes, in 13 $(0.8 \%)$ six codes, while three infants $(0.2 \%)$ received seven codes and three received eight codes.

When two digit codes were applied to each case, only 2063 codes remained. The other 786 ISC codes $(28 \%)$ were ignored because the conditions to which they referred were apparently secondary to other cardiac defects. After this transformation, 1225 cases $(76 \%)$ had only one two digit code, 320 $(20 \%)$ had two codes, $42(3 \%)$ had three, and 18 $(1 \%)$ had four.

In table $I$, a distinction is made between isolated and non-isolated cardiac defects and the number of cases for each malformation is given. This table shows that the proportion isolated/ non-isolated varies between the groups. If we consider nine groups (defined by the first digit of the code) the difference is highly significant $\left(\chi^{2}=298,8 \mathrm{df}, \mathrm{p}<0.001\right)$.

Among the 1605 infants, $200(12 \%)$ were reported to the Registry of Congenital Malformations only, whereas $1405(88 \%)$ were reported to the Child Cardiology Registry only or to both registries.

Table III shows the difference in survival between cases reported to the Registry of Congenital Malformations only and cases reported to the Child Cardiology Registry or to both

Table III Survival of infants with heart defects studied in the Cardiology Registry (CR), and the Registry of Congenital Malformations (RCM) alone.

\begin{tabular}{lclllll}
\hline & & \multicolumn{5}{c}{ Dead within (days) } \\
\cline { 3 - 6 } & Stillbirth & $<1$ & $1-7$ & $>7$ & Alive & Total \\
\hline CR & 0 & 11 & 99 & 301 & 920 & 1331 \\
RCM (alone) & 33 & 20 & 36 & 15 & 34 & 138 \\
\hline
\end{tabular}

registries. It can be seen that $64 \%$ of the cases reported to the Registry of Congenital Malformations alone $(89 / 138)$ were stillborn or died within seven days, whereas this was the case for only $8 \%$ of the cases reported to the Child Cardiology Registry (110/1331). Thirty three cases out of $138(24 \%)$ reported in the Registry of Congenital Malformations alone were alive and were nevertheless not reported to the Child Cardiology Registry.

Two hundred and two infants $(13 \%)$ had a known chromosomal anomaly. Table IV gives the number of infants for each anomaly. Among the cases with Down's syndrome, the most common cardiac malformations were endocardial cushion defects $(52 \%)$, septal defects $(28 \%)$, and truncus anomalies $(9 \%)$. Table $\mathrm{V}$ shows that the distribution of heart defect diagnoses in cases with

Table IV Distribution of the 202 cases of congenital heart defects that had a chromosomal anomaly.

\begin{tabular}{lc}
\hline Chromosomal anomaly & Number of cases \\
\hline Down's syndrome & 167 \\
Trisomy 18 & 15 \\
Trisomy 13 & 6 \\
Sex chromosome anomaly & 3 \\
Other & 12 \\
Total number of infants & $202^{\mathrm{a}}$
\end{tabular}

a One infant had both Down's syndrome and a sex chromosome anomaly. 
Down's syndrome differs from that in cases without a chromosomal anomaly $\left(\chi^{2}=1121,5 \mathrm{df}\right.$; groups 3, 4 and 5 have been combined, as have groups 7 and 8 , because of the small number of cases). The difference is still significant if the cases with endocardial cushion defects are removed $\left(\chi^{2}=61,4 \mathrm{df}\right)$, but disappears if the cases with cushion or septal defects are excluded $\left(\chi^{2}=1.73,3 \mathrm{df}, \mathrm{p}>0.05\right)$.

Among the 1605 cases, 45 were twins, that is approximately $2.8 \%$. The expected number of twins among 1605 births is only 31.6 (standardising for maternal age and year of birth $)\left(\chi^{2}=5.68\right.$, $1 \mathrm{df}, 0.025>\mathrm{p}>0.01)$. No twin pregnancy was found where both twins presented with congenital heart disease. Table VI shows the distribution of heart defect diagnoses in singletons and twins; no significant difference appears between them $\left(\chi^{2}=4.43,4 \mathrm{df}, \mathrm{p}>0.05\right.$ ) (groups $3,4,5$, and 6 , as groups 7 and 8 have been combined because of the small number of cases).

Table $V$ Distribution of the congenital heart defect diagnoses among cases with chromosomal anomaly; the nine groups issued from the two digit classification (see table I)

\begin{tabular}{|c|c|c|c|c|c|c|c|c|c|c|}
\hline & \multicolumn{9}{|c|}{ Heart defect } & \multirow[b]{2}{*}{ Total } \\
\hline & 1 & 2 & 3 & 4 & 5 & 6 & 7 & 8 & 9 & \\
\hline Cases without chromosome anomaly & 624 & 409 & 29 & 61 & 127 & 76 & 130 & 201 & 172 & 1829 \\
\hline $\begin{array}{l}\text { Down's syndrome } \\
\text { Trisomy } 18 \\
\text { Trisomy } 13 \\
\text { Sex chromosomal anomaly } \\
\text { Other }\end{array}$ & $\begin{array}{r}17 \\
4 \\
2 \\
1 \\
7\end{array}$ & $\begin{array}{r}53 \\
9 \\
4 \\
0 \\
2\end{array}$ & $\begin{array}{l}4 \\
0 \\
0 \\
0 \\
0\end{array}$ & $\begin{array}{l}0 \\
0 \\
0 \\
0 \\
0\end{array}$ & $\begin{array}{l}1 \\
1 \\
0 \\
0 \\
1\end{array}$ & $\begin{array}{r}99 \\
2 \\
0 \\
0 \\
1\end{array}$ & $\begin{array}{l}7 \\
1 \\
0 \\
1 \\
0\end{array}$ & $\begin{array}{l}6 \\
0 \\
1 \\
1 \\
3\end{array}$ & $\begin{array}{l}4 \\
1 \\
1 \\
0 \\
1\end{array}$ & $\begin{array}{r}191 \\
18 \\
8 \\
3 \\
15\end{array}$ \\
\hline
\end{tabular}

Table VI Distribution of congenital heart defect diagnoses among singletons and twins. Infants with a chromosomal anomaly are not included.

\begin{tabular}{lrrrrrrrrrrr}
\hline & \multicolumn{1}{l}{ Heart defect } & 1 & & & & & \\
\cline { 2 - 11 } & 1 & 2 & 3 & 4 & 5 & 6 & 7 & 8 & 9 & Total \\
\hline Singletons & 562 & 373 & 25 & 50 & 117 & 70 & 113 & 179 & 153 & 1642 \\
Twins & 16 & 11 & 1 & 2 & 2 & 3 & 6 & 9 & 3 & 53
\end{tabular}

Table VII Distribution of infants with congenital heart defects per five year maternal age class.

\begin{tabular}{|c|c|c|c|c|c|c|c|c|}
\hline & \multicolumn{7}{|c|}{ Maternal age (years) } & \multirow[b]{2}{*}{ Total } \\
\hline & $<20$ & $20-24$ & $25-29$ & $30-34$ & $35-39$ & $40-44$ & $>44$ & \\
\hline $\begin{array}{l}\text { Number of cases } \\
\text { Prevalence at birth } \\
\text { Number of cases } \\
\text { Prevalence at birth }\end{array}$ & $\begin{array}{l}41 \\
1.96 \\
38 \\
1.81\end{array}$ & $\begin{array}{l}356 \\
2.56 \\
325 \\
2.33\end{array}$ & $\begin{array}{l}548 \\
2.61 \\
496 \\
2.36\end{array}$ & $\begin{array}{l}428 \\
3.04 \\
366 \\
2.60\end{array}$ & $\begin{array}{l}189 \\
3.53 \\
149 \\
2.78\end{array}$ & $\begin{array}{l}23 \\
2.79 \\
13 \\
1.58\end{array}$ & $\begin{array}{l}3 \\
11.3 \\
0 \\
0\end{array}$ & $\begin{array}{l}1588 \\
2.77 \\
1387 \\
2.42\end{array}$ \\
\hline Number of births & 20952 & 139289 & 210086 & 140992 & 53593 & 8244 & 266 & 573422 \\
\hline
\end{tabular}

a Infants with chromosomal anomaly not included.

Table VIII Rates between observed and expected numbers of congenital heart defects according to the age of the mother after stratification for parity. Infants with a chromosomal anomaly are not included.

\begin{tabular}{lllllll}
\hline \multicolumn{7}{c}{ Age of the mother (years) } \\
\cline { 2 - 7 } & $<20$ & $20-24$ & $25-29$ & $30-34$ & $35-39$ & $>39$ \\
\hline Observed number (O) & 36 & 314 & 479 & 341 & 139 & 12 \\
Expected numbers (E) & 39 & 290 & 482 & 349 & 139 & 23 \\
Number of births & 20871 & 137811 & 207848 & 138761 & 52970 & 8456 \\
Ratio O/E & 0.92 & 1.08 & 0.99 & 0.98 & 1.00 & 0.52 \\
$95 \%$ Confidence interval & $0.66-1.27$ & $0.97-1.21$ & $0.91-1.09$ & $0.88-1.09$ & $0.85-1.18$ & $0.30-0.92$ \\
\hline
\end{tabular}

Table IX Rates between observed and expected numbers of congenital heart defects according to the parity after stratification for maternal age. Infants with a chromosomal anomaly are not included.

\begin{tabular}{|c|c|c|c|c|}
\hline & \multicolumn{4}{|l|}{ Parity } \\
\hline & 1 & 2 & 3 & $>3$ \\
\hline $\begin{array}{l}\text { Observed numbers }(\mathrm{O}) \\
\text { Expected numbers }(\mathrm{E}) \\
\text { Number of births } \\
\text { Ratio } \mathrm{O} / \mathrm{E} \\
95 \% \text { Confidence interval }\end{array}$ & $\begin{array}{l}517 \\
659 \\
287069 \\
0.78 \\
0.72-0.86\end{array}$ & $\begin{array}{l}472 \\
403 \\
171400 \\
1.17 \\
1.07-1.28\end{array}$ & $\begin{array}{l}236 \\
189 \\
78954 \\
1.25 \\
1.10-1.42\end{array}$ & $\begin{array}{l}96 \\
70 \\
29294 \\
1.37 \\
1.13-1.68\end{array}$ \\
\hline
\end{tabular}

Among 1605 infants, 1588 had information on maternal age. Table VII gives the distribution of cases with congenital heart disease per five year maternal age class. A distinction is made between infants with or without a known chromosomal anomaly. Tables VIII and IX illustrate the effect of maternal age and parity on congenital heart disease. Infants with a chromosomal anomaly were removed here because of the well known association between maternal age and trisomy. After standardisation for parity, it appears that maternal age has no effect on the prevalence of congenital heart disease except a possible underrisk for women above 39 years of age.

When parity is studied after standardisation for maternal age, an under-risk for parity 1 is observed and an increasing risk with increasing parity appears. When the same study is performed within each one of the nine groups, the parity effect cannot solely be explained by one specific group.

Approximately 19\% (261/1403) of all infants with no known chromosomal anomaly presented at least one extracardiac malformation. In table $\mathrm{X}$, a distinction is made between isolated (only one diagnosis) and non-isolated (several diagnoses) extracardiac malformations. This table gives an idea of the distribution within the different congenital heart disease groups. It appears that the proportion of cases with extracardiac malformations varied significantly between groups, with particularly high proportions for groups 2 and 3 (septal defects and mitral valve anomalies respectively) and for cases with multiple congenital heart defects. On the other hand, only a low proportion is observed for group 5 (hypoplastic left heart syndrome). A test for heterogeneity gives $\chi^{2}=24.7,7 \mathrm{df}, \mathrm{p}<0.001$ (groups 3 and 4 have been combined). If we compare the two first groups of table $\mathrm{X}$, that is truncus anomalies (code 1) and septal defects (code 2), a significant difference appears. Among 452 infants that present a truncus malformation, $13 \%$ present an extracardiac anomaly (60 cases) against $24 \%$ in the case of septal malformations $(60 / 254)\left(\chi^{2}=12.3,1 \mathrm{df}, \mathrm{p}<0.001\right)$.

Among infants without chromosomal anomaly, 1403 had information on sex. The male-female ratio among them is 1.24 , that is approximately $55.4 \%$ males (775/1398; in five infants the sex was not known). This differs significantly from the normal sex ratio of $51.5 \%$ males $\left(\chi^{2}=8.67,1 \mathrm{df}\right.$, $0.01>p>0.001)$. Heterogeneity between the nine congenital heart disease groups has been tested by calculating a $\chi^{2}$ at $7 \mathrm{df}$ (groups 3 and 4 have been combined). The difference between them is highly significant $\left(\chi^{2}=40.3,7 \mathrm{df}, \mathrm{p}<0.001\right)$. The sex ratio has also been determined in each group and subgroup for cases presenting only one cardiac malformation. The number of cases for each defect is given in table XI with the corresponding $\chi^{2}$ based on the sex ratio of the normal population $(51.5 \%$ of males and $48.5 \%$ of females).

An excess of males is observed for transposition of the great vessels (code 11), hypoplastic left heart syndrome (code 50), and coarctation of the aorta (code 80), whereas for endocardial cushion defect (code 60) and ductus anomalies (code 72), females are in excess. 
Table X Distribution (according to the type of heart defect) of the extracardiac malformations as isolated (one malformation) or non-isolated ( $>1$ malformation). Infants with a chromosomal anomaly are not included.

\begin{tabular}{|c|c|c|c|c|c|}
\hline \multirow[b]{2}{*}{ Two digit code } & \multicolumn{3}{|c|}{ Cases with extracardiac malformation } & \multirow[b]{2}{*}{ Total } & \multirow[b]{2}{*}{ Percentage } \\
\hline & 1 malformation & $>1$ malformations & Total & & \\
\hline $\begin{array}{l}1 \\
2 \\
3 \\
4 \\
5 \\
5 \\
6 \\
7 \\
8 \\
9\end{array}$ & $\begin{array}{r}40 \\
33 \\
1 \\
0 \\
4 \\
4 \\
5 \\
8 \\
4\end{array}$ & $\begin{array}{r}20 \\
27 \\
2 \\
4 \\
2 \\
3 \\
1 \\
2 \\
0\end{array}$ & $\begin{array}{r}60 \\
60 \\
3 \\
4 \\
6 \\
7 \\
6 \\
10 \\
4\end{array}$ & $\begin{array}{r}452 \\
254 \\
4 \\
38 \\
108 \\
42 \\
51 \\
64 \\
41\end{array}$ & $\begin{array}{r}13.3 \\
23.6 \\
75.0 \\
10.5 \\
5.6 \\
16.7 \\
11.8 \\
15.6 \\
9.8\end{array}$ \\
\hline $\begin{array}{l}\text { Infants with } \\
\text { more than one } \\
\text { heart diagnosis }\end{array}$ & 48 & 53 & 101 & 349 & 28.9 \\
\hline Total & 147 & 114 & 261 & 1403 & 18.6 \\
\hline
\end{tabular}

The sex ratio observed for coarctation of the aorta (code 80) was different than that observed in the group of artery malformations (codes 70-72) $\left(\chi^{2}=12.1,1 \mathrm{df}, \mathrm{p}<0.001\right)$ which explains the exclusion of coarctation from this group.

\section{Discussion}

Data on the prevalence at birth of congenital heart disease vary widely in published reports, depending on the criterion for the selection of the cases and the length of the follow up period. This makes the results difficult to compare. ${ }^{4}$ In this study, the entry criterion was a heart defect detected by echocardiography, cardiac catheterisation, at operation or necropsy, or giving serious clinical signs or death during the first week of life.

In their study on monitoring of congenital cardiac defects in Sweden, Carlgren $e t a l^{5}$ considered that the ascertainment obtained by the Child Cardiology Registry combined with the Registry of Congenital Malformations was probably enough to permit adequate monitoring. They estimated a final ascertainment of approximately $85 \%$, which should be roughly the same in this study where both registries were used. They also observed that if all infants with a diagnosis of congenital heart defects are considered, this represents a prevalence at birth of approximately nine per 1000 . Many of these infants had only a "suspected" or unspecified heart defect and were only reported in the Medical Birth Registry. If

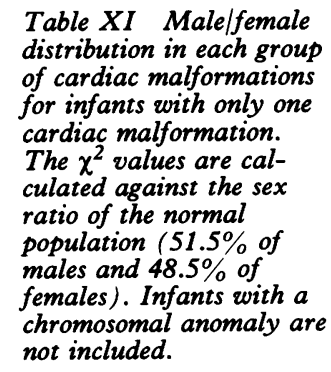

\begin{tabular}{lrrlrl}
\hline $\begin{array}{l}\text { Two digit } \\
\text { code }\end{array}$ & Males & Females & $\begin{array}{l}\text { Sex } \\
\text { ratio }\end{array}$ & \multicolumn{1}{l}{$\chi^{2}$} & \multicolumn{1}{l}{$p$} \\
\hline 10 & 20 & 16 & 1.25 & 0.24 & $>0.05$ \\
11 & 116 & 56 & 2.07 & 17.50 & $<0.001$ \\
12 & 12 & 10 & 1.20 & 0.08 & $>0.05$ \\
13 & 110 & 78 & 1.41 & 3.70 & $>0.05$ \\
14 & 21 & 11 & 1.91 & 2.56 & $>0.05$ \\
15 & 1 & 0 & - & - & $>0.05$ \\
20 & 16 & 15 & 1.07 & 0 & $>0.05$ \\
21 & 85 & 78 & 1.09 & 0.03 & $>0.05$ \\
22 & 11 & 18 & 0.61 & 2.13 & $>0.05$ \\
23 & 16 & 14 & 1.14 & 0.04 & $>0.05$ \\
30 & 1 & 3 & 0.33 & - & $>0.05$ \\
40 & 12 & 14 & 0.86 & 0.30 & $>0.05$ \\
41 & 4 & 8 & 0.50 & 1.59 & $>0.05$ \\
50 & 70 & 38 & 1.84 & 7.67 & $<0.01,>0.001$ \\
60 & 14 & 28 & 0.50 & 5.55 & $<0.025,>0.01$ \\
70 & 4 & 7 & 0.57 & 1.01 & $>0.05$ \\
71 & 2 & 5 & 0.40 & - & $>0.05$ \\
72 & 10 & 23 & 0.43 & 5.94 & $<0.025,>0.01$ \\
80 & 41 & 23 & 1.78 & 4.04 & $<0.025,>0.01$ \\
90 & 23 & 18 & 1.28 & 0.35 & $>0.05$ \\
Total & 589 & 463 & 1.27 & 8.49 & $<0.01,>0.001$ \\
\hline
\end{tabular}

these were removed, the prevalence at birth was almost three per 1000 .

It is possible that some infants have an onset of cardiac symptoms after the perinatal period and die before the age of one year without being reported to the Child Cardiology Register. These infants may be identified by death certificates. In their study, Carlgren et al used death certificates as a further source of information. They found, however, that the diagnostic quality was very poor. It has to be underlined that a slightly lower ascertainment is often the price to pay for high diagnostic quality.

The prevalence at birth of 2.8 per 1000 found in the present study for the period 1981-1986 roughly agrees with the results of previous studies using similar selection criteria. Carlgren ${ }^{6}$ found a prevalence at birth of 6.4 per 1000 in Gothenburg, Sweden, with a follow up period of up to 16 years. If the congenital heart disease was confirmed by either catheterisation, surgery, or necropsy, the prevalence reached only four per 1000 .

In the New England regional infant cardiac program, Fyler $e t$ a $l^{7}$ found a prevalence at birth of 2.1 per 1000 for the period 1969-1974 with a follow up period of one year, and 2.5 per 1000 for the period 1975-1977. In the BaltimoreWashington infant study, Ferencz et $a l^{8}$ found a prevalence of 2.4 per 1000 when only cases confirmed by invasive methods were included.

In order to be able to study more homogeneous groups of cardiac defects, a subdivision of the material should be made. There is a vast number of different types of cardiac defects, often of considerable clinical difference. If each type should be studied as such, numbers would be low for many of the types and the power of an analysis would also be low. Different efforts have therefore been made to group the cardiac defects into larger groups with, hopefully, some common pathogenic pathway.

Ferencz et $a l^{8}$ distinguished the major structural cardiac malformations including conotruncal and major septation defects (transposition of the great vessels, Fallot's tetralogy, double outlet right ventricle, truncus arteriosus, endocardial cushion defect, total anomalous pulmonary venous return) and atresias (tricuspid atresia, pulmonary atresia, hypoplastic left heart syndrome) from the abnormalities most commonly found in the heart: valve and vessel lesions (pulmonary stenosis, aortic stenosis, coarctation), septal defects (ventricular and atrial septal defect), and patent ductus arteriosus.

In the Report of the New England regional infant cardiac program, ${ }^{7}$ the number of diagnostic categories was reduced to 21 , representing the commonly encountered and commonly grouped lesions.

Tikkanen and Heinonen ${ }^{9}$ distinguished six categories: ventricular septal defect, conus arteriosus, atrial septal defect, hypoplastic left heart syndrome, endocardial cushion defect, and other defects.

In this paper, the ISC diagnoses for each infant have been transformed into two digit codes. This embryological coding system is derived from Carlgren $e t a T^{5}$ and allows a further grouping by only considering the first digit of the code; nine groups are then obtained, thought to represent 
disturbances of different aspects of heart development. Such a classification reduces the variability that may exist in the reporting from different cardiology units and also forms groups with reasonably large numbers.

After our classification, 380 cases $(24 \%)$ with more than one code remained. Fyler et $a l^{7}$ and Carlgren $e t a{ }^{5}$ handled these cases by using a hierarchical system: a single diagnosis that best represented each infant was used. However, when this classification is performed by a computer, some problems may occur. All defects are reported as either present or absent without information on the functional importance of the defect. As pointed out by Fyler et $a l^{7}$ the hierarchical rule will classify an infant with aortic coarctation and ventricular septal defect as a coarctation even if the coarctation is minor and the septal defect large.

In this study, the infants with several cardiac diagnoses were left as such, but for each malformation a distinction was made between isolated and non-isolated defects. The proportion of cases of congenital heart disease in which more than one cardiac defect is present varies with type of defect.

The risk for having a congenital heart defect seems to be higher among twins than among singletons. This has been already reported. ${ }^{10} 11$ As suggested by Melnick and Myrianthopoulos ${ }^{12}$ and Berg et al, ${ }^{13}$ the twinning process itself may contribute to the development of a heart defect. Layde $e t$ al $^{14}$ reported an increased rate of patent ductus arteriosus and Fallot's tetralogy in twins. In our material, no malformation appears to be characteristic for twins but it is possible that the method used in this study for grouping the different heart defects is not suitable for that specific question.

An effect of parity is observed even after standardisation for maternal age. Between parity 1 and parity 4 the risk increase is approximately $70 \%$. It was not possible to identify any particular group of congenital heart disease that alone caused this trend. It is, however, difficult to show this as numbers are small in many groups and therefore confidence intervals are very large. The finding is difficult to explain and may be the result of an indirect effect.

No maternal age effect is observed after standardisation for parity when cases with a chromosomal anomaly are excluded. It appears from table VII that among mothers older than 35 years, 25\% of infants with a congenital heart defect have a chromosomal anomaly and thus could be detected by prenatal diagnosis.

The sex ratio found in this study agrees with the sex ratio observed by Fyler et al. ${ }^{7}$ In their report of the New England regional infant cardiac program, they found $53.7 \%$ of males out of a total of 2251 infants (55\% in our case). For the endocardial cushion defect only, they found $59 \%$ of females $(67 \%$ in our case). Among infants with hypoplastic left ventricle, they had a proportion of males of $66 \%$ against $65 \%$ in our study. Male and female children have thus a tendency to have different types of cardiac malformations.

The tendency to have associated extracardiac malformations appears to be different in the different groups of heart defects. We observed for example that this tendency was higher in the group of septal defects than in the group of truncus anomalies. The other differences observed between groups of defects, such as sex ratio and number of heart defect diagnoses, show that this classification may be suitable for further analyses of congenital heart defects.

Acutis $e t$ al $^{15}$ found that approximately $33 \%$ of infants with Down's syndrome had a congenital heart defect. Among 257 such cases, 16 were operated on for congenital heart disease $(6.2 \%)$. Among them six $(38 \%)$ had endocardial cushion defects, six had ventricular septal defects, two $(13 \%)$ had atrial septal defects, one $(6 \%)$ had a patent ductus arteriosus, and one had Fallot's tetralogy. In 1961, Rowe and Uchida ${ }^{16}$ found that in infants with Down's syndrome and cardiac defects, $36 \%$ had endocardial cushion defects, $33 \%$ had ventricular septal defects, $9 \%$ had atrial septal defects, $10 \%$ had patent ductus arteriosus and $1 \%$ had Fallot's tetralogy. In our study, the most common cardiac defects in Down's syndrome infants are also endocardial cushion defects and septal defects. The rate for endocardial cushion defects is higher in our study, while the rate for septal defects is lower, than in those quoted above. This may be the result of different definition criterion for each malformation.

The study was made possible by a grant from the Medical Faculty, University of Lund, Sweden.

1 Källen B. Search for teratogenic risks with the aid of malformation registries. Teratology $1987 ; 35: 47-52$

2 Källèn B, Winberg J. A Swedish register of congenita malformations. Experience with continuous registration during 2 years with special reference to multiple malformations. Pediatrics 1968; 41: 765-76.

3 International Society of Cardiology. Classification of heart disease in childhood. The Netherlands: VRB Offsetdrukkerij, Groningen, 1970.

4 World Health Organization working group on congenital heart disease in Europe (Document EURO 8213). Copenhagen: WHO, 1972.

5 Carlgren L-E, Ericson A, Källen B. Monitoring of congenital cardiac defects. Pediatr Cardiol 1987; 8: 247-56. Carlgren L-E. The incidence of congenital heart disease in children born in Gothenburg 1941-1950. Br Heart $\mathcal{F} 1959$; 21: 40-50.

7 Fyler DC, Buckley LP, Hellenbrand WE, et al. Report of the New England regional infant program. Pediatrics 1980; 65 [suppl]: 375-461.

8 Ferencz C, Rubin JD, McCarter RJ, et al. Congenital heart disease: prevalence at livebirth: the Baltimore-Washington infant study. Am $\mathcal{F}$ Epidemiol 1985; 121 : 31-6.

9 Tikkanen J, Heinonen OP. Maternal exposure to chemical and physical factors during pregnancy and cardiovascular malformations in the offspring. Teratology 1991; 43: 591600

10 Källén B. Congenital malformations in twins. A population study. Acta Genet Med Gemellol 1986; 35: 167-78.

11 Windham GC, Bjerkedal T. Malformations in twins and their siblings, Norway, 1967-1979. Acta Genet Med Gemellol 1984; 33: 87-95.

12 Melnick M, Myrianthopoulos NC. The effect of chorion type on normal and abnormal development variation in monozygous twins. Am $f$ Med Genet 1979; 4: 147-56.

13 Berg KA, Astemborski JA, Boughman JA, Ferencz C. Congenital cardiovascular malformations in twins and triplets from a population-based study. Am $f$ Dis Child

14 Layde PM, Erickson JD, Falek A, McCarthy BJ. Congenital malformations in twins. Am $\mathcal{F}$ Hum Genet 1980; 32: 69-78. 15 Acutis MS, Forni GL, Barbano GC, Schiavetti P, RasoreQuartino A. Aspetti di patologia congenita ed acquisita nel bambino con la sindrome di Down. Studio di 257 casi. In: Bricarelli FD, Inglese C, Moretti A, Rasore-Quartino A, eds. $\mathrm{Ce} P \mathrm{Pi}$ Aspetti epidemiologici, gentici, clinici, riabilitativi e sociali della sindrome di Down. $V$ convegno: "Un futuro per $i$ bimbi Down". Genova, 1-3 December, 1983: 209-16.

16 Rowe RD, Uchida IA. Cardiac malformations in mongolism, a prospective study of 184 mongoloid children. Am $\mathcal{F}$ Med 1961; 31: 726-35. 